OPEN ACCESS

Edited by:

Guido Santos-Rosales, University Hospital Erlangen,

Germany

Reviewed by:

Martin Diener,

University of Giessen, Germany

Pramod Kumar,

National Institute of Cancer

Prevention and Research (ICMR),

India

${ }^{*}$ Correspondence:

Diliana Pérez-Reytor

d.perez@uautonoma.c

Katherine García

katherine.garcia@uautonoma.cl

Specialty section:

This article was submitted to

Membrane Physiology and

Membrane Biophysics,

a section of the journal

Frontiers in Physiology

Received: 07 January 2021 Accepted: 26 April 2021

Published: 24 May 2021

Citation:

Pérez-Reytor D, Puebla C, Karahanian E and García K (2021) Use of Short-Chain Fatty Acids for

the Recovery of the Intestinal

Epithelial Barrier Affected by Bacterial Toxins.

Front. Physiol. 12:650313.

doi: 10.3389/fphys.2021.650313

\section{Use of Short-Chain Fatty Acids for the Recovery of the Intestinal Epithelial Barrier Affected by Bacterial Toxins}

\author{
Diliana Pérez-Reytor ${ }^{1 *}$, Carlos Puebla ${ }^{2}$, Eduardo Karahanian ${ }^{1}$ and Katherine García ${ }^{1 *}$ \\ 'Instituto de Ciencias Biomédicas, Facultad de Ciencias de la Salud, Universidad Autónoma de Chile, Santiago, Chile, \\ ${ }^{2}$ Instituto de Ciencias de la Salud, Universidad de O'Higgins, Rancagua, Chile
}

Short-chain fatty acids (SCFAs) are carboxylic acids produced as a result of gut microbial anaerobic fermentation. They activate signaling cascades, acting as ligands of G-proteincoupled receptors, such as GPR41, GPR43, and GPR109A, that can modulate the inflammatory response and increase the intestinal barrier integrity by enhancing the tight junction proteins functions. These junctions, located in the most apical zone of epithelial cells, control the diffusion of ions, macromolecules, and the entry of microorganisms from the intestinal lumen into the tissues. In this sense, several enteric pathogens secrete diverse toxins that interrupt tight junction impermeability, allowing them to invade the intestinal tissue and to favor gastrointestinal colonization. It has been recently demonstrated that SCFAs inhibit the virulence of different enteric pathogens and have protective effects against bacterial colonization. Here, we present an overview of SCFAs production by gut microbiota and their effects on the recovery of intestinal barrier integrity during infections by microorganisms that affect tight junctions. These properties make them excellent candidates in the treatment of infectious diseases that cause damage to the intestinal epithelium.

Keywords: short-chain fatty acid, bacterial toxins, tight junctions, epithelial barrier, zonula occludens toxins

\section{INTRODUCTION}

The intestinal microbiota plays a critical role in the degradation of indigestible food components, immune system function, modulation of the activity of enteric and central nervous systems, reinforcement of the epithelial barrier, protection against pathogens and their toxins, and producing several compounds that influence the nutritional and health status of the host (Karl et al., 2018; Fan and Pedersen, 2020). Low-fiber diets (Fan and Pedersen, 2020), stressors, or even the use of antibiotics (Karl et al., 2018) led to an imbalanced intestinal microbiota (dysbiosis) that can trigger inflammatory bowel disease (IBD), allergic, autoimmune, and metabolic diseases (O'Connor, 2013; Soldavini and Kaunitz, 2013; Sturgeon and Fasano, 2016), and certain types of cancer (Paul et al., 2018). Studies linking intestinal microbiota with nutritional status focused on the degradation of indigestible fiber by bacterial enzymes and metabolites (O'Connor, 2013; Frampton et al., 2020). Several studies showed that 
microbial-generated short-chain fatty acids (SCFAs) in the gut might play a key role in the prevention and treatment of IBD (D'Souza et al., 2017; Parada Venegas et al., 2019). SCFAs are carboxylic acids with aliphatic tails of less than six carbons where acetate $(\mathrm{C} 2)$, propionate $(\mathrm{C} 3)$, and butyrate $(\mathrm{C} 4)$ represent the major end-products of gut microbial fermentation (Pingitore et al., 2019; Hiroko et al., 2020). These molecules are readily absorbed in the colon where they serve as an energy source for colonocytes and aid in the repair of the wounded epithelium (Suzuki et al., 2008; Ganapathy et al., 2013). SCFAs also help to regulate glucose and lipid metabolism, which has important implications for the energy homeostasis of the host (Hiroko et al., 2020). Interestingly, SCFAs are associated with changes in tight junction (TJ) proteins expression and distribution (Hiippala et al., 2018). Recent evidence points to a direct role for the GPR43, GPR41, and GPR109A receptors in mediating the protective roles of SCFAs in IBD (Kim et al., 2014; D'Souza et al., 2017; Pan et al., 2018), as well as in controlling the production of cytokines and chemokines by intestinal epithelial cells (IECs; D’Souza et al., 2017).

Colonization of the proximal intestine by pathogenic microorganisms can lead to a permeable gut by the action of secreted toxins (Fasano, 2012). Specifically, these toxins can alter cell physiology through various mechanisms, either being directly responsible for the pathology of the disease or favoring other bacterial processes such as manipulation of the immune response and penetration of host barriers, among others (UgaldeSilva et al., 2016). Thus, the epithelial barrier tightly controls antigen trafficking through paracellular pathways and is essential for the maintenance of normal functioning of the intestine (Ugalde-Silva et al., 2016; Pérez-Reytor et al., 2018). SCFAs have a protective effect against bacterial pathogens by maintaining the integrity of the epithelial barrier (D'Souza et al., 2017). Therefore, the production of adequate and balanced SCFAs by healthy gut microbiota is an important factor that prevents infection by common foodborne pathogens. Here, we aim to provide an overview of microbial SCFAs production in the gut and their signaling associated with the recovery process of the intestinal barrier after being damaged by bacterial toxins.

\section{PRODUCTION OF SCFAS AND THEIR ASSOCIATED SIGNALING}

\section{Microbiota and Intestinal Production of SCFAs}

In physiological conditions and absence of bacterial enteric infections, the small intestine harbors a complex microbial community of approximately $10^{3}-10^{7}$ microbial cells/gram. This microbiota is less diverse and abundant than the colonic microbiota with $\approx 10^{12}$ cells/gram (Martinez-Guryn et al., 2018). An important metabolic activity of the intestinal microbiota is the fermentation of non-digestible starch and fiber, which generates SCFAs as the principal end product (O'Connor, 2013). SCFAs have different production rates and their concentrations vary within the human colon: acetate is in the range of $20-43 \mathrm{mmol} / \mathrm{L}$, while butyrate and propionate have been reported to $6-15$ and $6-13 \mathrm{mmol} / \mathrm{L}$, respectively (Cox et al., 2009). Butyrate is mostly produced by Gram-positive Firmicutes, while acetate and propionate are mainly produced by Gram-negative Bacteroidetes (Louis and Flint, 2009, 2017). In this sense, some investigations have shown that dysbiosis in IBD patients is associated with a reduction in the number of butyrate-producing firmicute bacteria (Sokol et al., 2007). Additionally, mucosal immunity is greatly influenced by dietary fiber and microbial SCFAs. Acetate and butyrate improve goblet cell differentiation and mucus production, necessary for a healthfuller epithelium structure (Yap and Mariño, 2018), protecting against pathogens that degrade mucus layer for invasion and/or uptake of mucus-derived nutrients.

\section{SCFAs Transport and Their Cell Surface Receptors}

Short-chain fatty acids can enter IECs through passive diffusion or by carrier-mediated transport: sodium-coupled monocarboxylate transporter 1 (SMCT1) and $\mathrm{H}^{+}$-coupled monocarboxylate transporter 1 (MCT1; Gupta et al., 2006). SMCT1 is mainly expressed in the distal colon, whereas MCT1 is expressed in the colon but also in monocytes, granulocytes, and lymphocytes (Parada Venegas et al., 2019). In addition to being transported into cells, SCFAs can act directly as signal molecules for some G-protein-coupled receptors such as GPR41 (FFAR3), GPR43 (FFAR2), and GPR109A (HCAR2; Ulven, 2012; Ganapathy et al., 2013; Kim et al., 2014; Sun et al., 2017; Feng et al., 2018; Pingitore et al., 2019). GPR41 is equally activated by propionate and butyrate, whereas GPR43 is activated by acetate and propionate more than butyrate (Parada Venegas et al., 2019; Hiroko et al., 2020). GPR41 and GPR43 are differentially expressed in intestinal cells, adipocytes, and phagocytes (Suzuki et al., 2008; Ganapathy et al., 2013; Kim et al., 2014; Pan et al., 2018; Pingitore et al., 2019) and differ in their downstream signaling cascades: while GPR41 binds only to Goi decreasing intracellular cAMP levels, GPR43 can bind to either Goi or Goq decreasing cAMP or increasing the generation of diacylglycerol (DAG) and inositol triphosphate, respectively, promoting the mobilization of $\mathrm{Ca}^{2+}$ (Pan et al., 2018; Pingitore et al., 2019). When GPR43 inhibits cAMP signaling, protein kinase A (PKA) activation is prevented (Pan et al., 2018). On the other hand, the effect of butyrate on DAG-mediated protein kinase $\mathrm{C}$ (PKC) activation is not fully studied (Miao et al., 2016). GPR109A, which is expressed in adipose tissue and colon, is activated by butyrate (Parada Venegas et al., 2019) and it was shown to provide a protective effect against colitis (Macia et al., 2015).

\section{SCFAS PROMOTE THE FUNCTION OF THE EPITHELIAL BARRIER UPREGULATING THE TJ PROTEINS}

\section{Regulation of $\mathrm{TJ}$}

Epithelial cells are the first line of defense against bacteria and their toxins (Banan et al., 2001; Ceelen et al., 2011; Hiippala et al., 2018). These cells are held together by different 
intercellular junctions: TJ, adherent junctions, gap junctions, and desmosomes (Figure 1; Sturgeon and Fasano, 2016). The claudins, occludins, and the zonula occludens-associated ( $\mathrm{ZO})$ proteins 1 , 2, and 3 in the TJ (Pérez-Reytor et al., 2018) are located in the most apical side of the basolateral membrane, forming the paracellular pathways that regulate the passage of ions, solutes, bacteria, and toxins across the epithelial monolayer (Anderson and Van Itallie, 2009; Jain et al., 2011) and are also responsible for maintaining/ imparting cell polarity (Anderson and Van Itallie, 2009; Maynard et al., 2012). The integrity of the TJ structure largely depends on the expression levels of TJ proteins (Wang et al., 2012).

Zonulin is the main regulator of intestinal permeability due to its action on TJ (Salama et al., 2006; Sturgeon and Fasano, 2016). Zonulin-induced stimulation of protease-activated receptor 2 (PAR2; Vergnolle, 2005), which is located in the basolateral face, increases the intestinal permeability through the redistribution of ZO-1, occludin, and F-actin (Fasano, 2002, 2012; Goldblum et al., 2011). Thereby, zonulin increases intestinal permeability to bacterial components that strongly activate the innate immune response of the intestine, and its upregulation has been linked to the development of several chronic and autoimmune inflammatory disorders such as celiac disease (Sapone et al., 2006). Additionally, the participation of several tyrosine kinases, such as
c-Src (Basuroy et al., 2003) and c-Yes (Chen and Lu, 2003), serine/threonine protein kinases, such as PKC (Cario et al., 2007), MAPK (mitogen-activated protein kinases), and PKA (Jain et al., 2011), in the proper functioning of TJ has been demonstrated. This would strongly support the role of different types of kinases as mediators in the effects of activation of SCFA receptors on proper epithelial barrier function.

In Caco-2 cells, inflammatory mediators, such as tumor necrosis factor- $\alpha$ (TNF- $\alpha$, Ma et al., 2005) and interferon- $\gamma$ (IFN- $\gamma$ ), dissociate TJ (Jain et al., 2011), mainly through changes in the expression and localization of TJ proteins and in actin cytoskeletal structure (Sturgeon and Fasano, 2016). TNF- $\alpha$ also plays a central role in intestinal inflammation associated with Crohn's disease (CD) and other inflammatory disorders (Ye et al., 2006). In general, intestinal inflammation, commensal microbes, and dietary components are among the main factors affecting epithelial permeability (Hiippala et al., 2018).

\section{SCFAs Restore the Integrity of the Intestinal Epithelial Barrier}

Butyrate has been shown to regulate proliferation, apoptosis, and cell differentiation of the gastrointestinal epithelium (Miao et al., 2016). Butyrate was able to recover the barrier

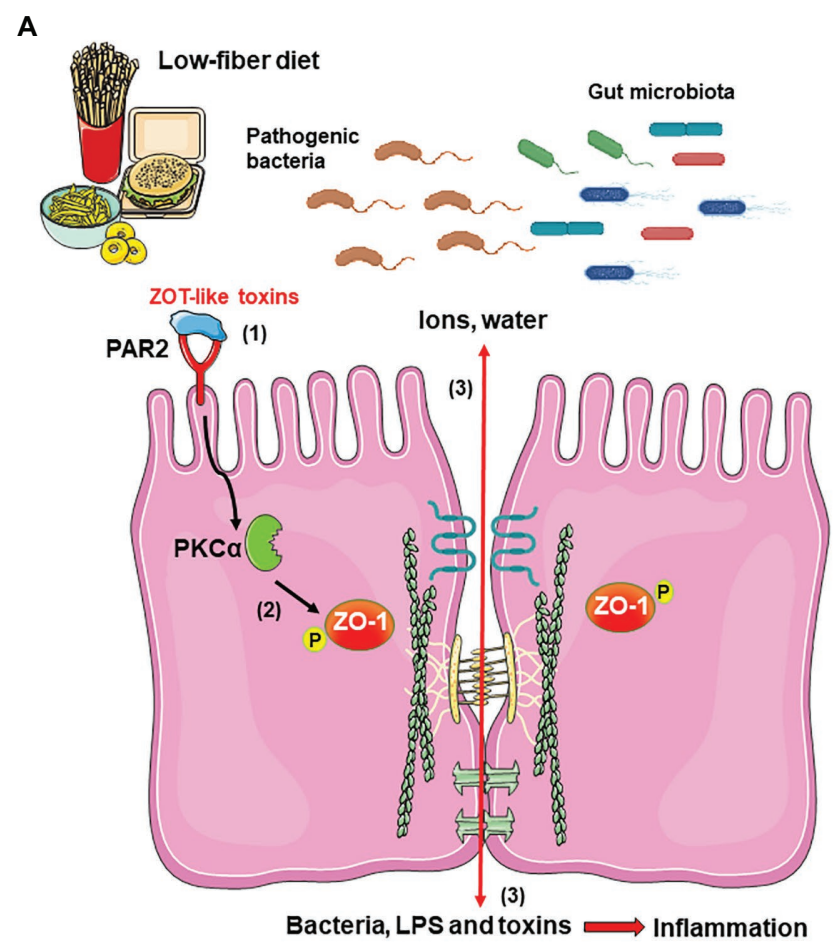

B

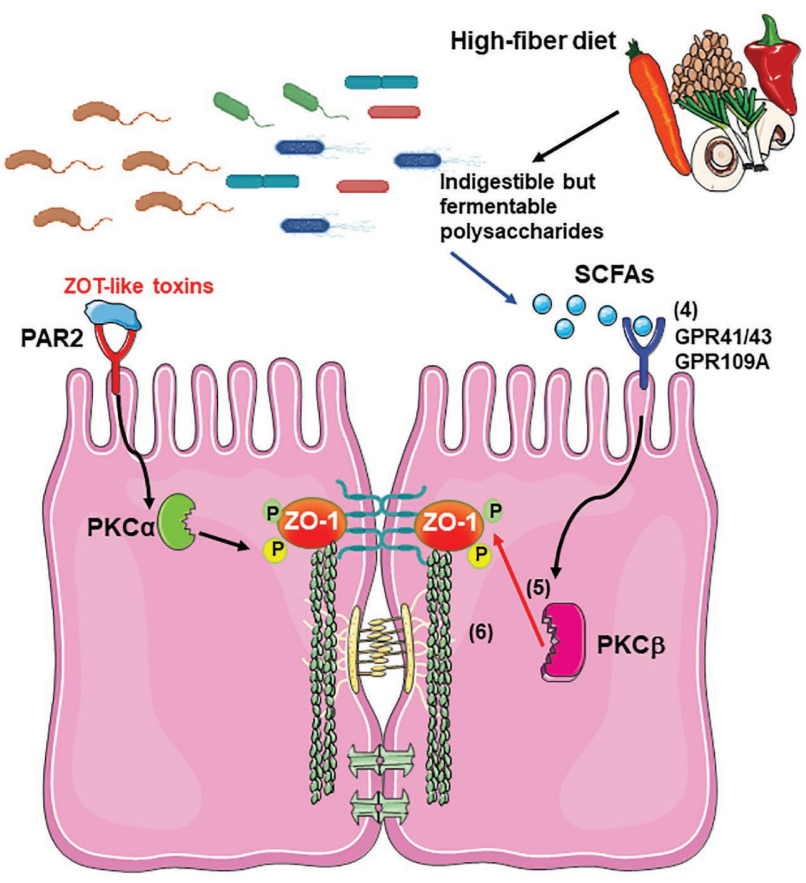

FIGURE 1 | Proposed mechanism for short-chain fatty acids (SFCAs) effects in improvement of the epithelial barrier damaged by bacterial Zot-like toxins. (A) During infection with pathogenic bacteria and in the presence of a low-fiber diet, Zot-like toxins interact with PAR-2 (1), which signals and activates PKC $\alpha$ (2). PKC $\alpha$ catalyzes the phosphorylation of ZO-1 at specific residues, which disconnects it from occludin, claudin, and F-actin (2), with the subsequent loss of tight junction (TJ) integrity. The disassembling of TJ allows the massive filtration of ions and water into the lumen of the intestine, as well as the entry of bacteria and bacterial components, such as LPS and other toxins, which promotes a severe inflammatory response (3). (B) The possible activation of GPR41, GPR43, and/or GPR109A by acetate, propionate, and butyrate produced by gut microbiota from dietary fiber (4) activates PKC $\beta$ (5), which phosphorylates ZO-1 at different residues than PKC $\alpha$, allowing its reconnection with occludin, claudin, and F-actin (6), thus recovering the structure and function of the TJ and counteracting the Zot effect. The figure was produced using Servier Medical Art (https://smart.servier.com/). 
function through the positive regulation of the expression of claudin-1, ZO-1, and occludin in Cdx2-IEC and Caco-2 cells, resulting in increased transepithelial electrical resistance (TEER; Peng et al., 2009; Wang et al., 2012; Miao et al., 2016); the effect of butyrate on the epithelial barrier may be mediated by upregulation of TJ proteins via activation of AMP-activated protein kinase (AMPK; Peng et al., 2009). On the other hand, Valenzano et al. (2015) showed that Caco-2 cell monolayers treated with $5 \mathrm{mM}$ butyrate changed TJ proteins expression levels: claudin- 2 decreased by $90 \%$, and claudin- 7 increased by $376 \%$, suggesting that butyrate might also regulate the remodeling of the TJ for maturing the barrier function. Yan and Ajuwon (2017) demonstrated that butyrate reduced the negative effect of lipopolysaccharide (LPS) on epithelial integrity through an increase in the synthesis of claudin-3 and claudin-4 via activation of the Akt signaling pathway in IPEC-J2 cells.

In colonocytes, SCFAs modulate several processes involving members of the PKC family, which require cofactor calcium and DAG to be activated (Rickard et al., 2000). Authors suggested that PKC $\beta 1$ activation may be required for the probiotic-mediated protection of $\mathrm{TJ}$ from $\mathrm{H}_{2} \mathrm{O}_{2}$ (Seth et al., 2008) and that the reassembly of TJ in Caco-2 cells by sodium butyrate is because of the increased activity of PKC $\beta 2$ (Miao et al., 2016). The role of PKC mediating the effects of SCFAs were also demonstrated in studies by Kimura et al. (2013), which showed that acetate-mediated activation of GPR43 signals via the PLC-PKC-PTEN pathway in adipocytes. However, the signaling pathways activated by SCFAs appear to depend on the cell type and function being examined (Parada Venegas et al., 2019).

Short-chain fatty acids have also shown the effects against the production of proinflammatory cytokines (e.g., IL-6, IL-1 $\beta$, IL-8, and TNF- $\alpha$ ) by decreasing NF- $\kappa \mathrm{B}$ activation in TLR-induced responses, in IECs (Lin et al., 2015; Russo et al., 2019). The inhibition of histone deacetylases activity, mainly by butyrate and propionate, induces anti-inflammatory activities on intestinal cells, macrophages, and dendritic cells (Sun et al., 2017; Li et al., 2018). Additionally, butyrate potently inhibits the production of LPS-induced IL- $1 \beta$ and TNF- $\alpha$ in peripheral blood mononuclear cells by increasing the expression of GPR43 and also inhibiting the production of IL-6 to a lesser extent (D'Souza et al., 2017). Butyrate also promotes the correct activation and functioning of the inflammasome in colonic epithelium, allowing rapid recognition of invading microbes, thus avoiding further damage to the epithelial barrier (Singh et al., 2014; Macia et al., 2015).

\section{SCFAS AND MICROORGANISMS AFFECTING THE INTEGRITY OF THE EPITHELIAL BARRIER}

\section{SCFAs as a Treatment in Diseases Caused by Foodborne Pathogens}

The intestinal microbiota is essential for the development and functional maturation of the gut immune system. Hence, a complex interaction between the host immune system and the microbiota is required for gut homeostasis (Maynard et al., 2012). In this sense, ulcerative colitis (UC) and $\mathrm{CD}$ are gastrointestinal disorders associated with dysbiosis and dysfunction of the intestinal barrier integrity induced by toxins and pathogens (Ulven, 2012; Yan and Ajuwon, 2017; Parada Venegas et al., 2019). It was postulated that dietary fiber-derived SCFAs promote the function of the intestinal epithelial barrier and help repair damaged epithelium. Even more, several intestinal diseases, particularly those involving mucosal inflammation, are believed to result from an imbalance in SCFAs concentrations (Soldavini and Kaunitz, 2013; Macia et al., 2015).

Among SCFAs, butyrate has received the most attention for its effects on colonic health (Singh et al., 2014). Butyrate has shown some promising effects in the treatment of UC, while propionate's anti-inflammatory effect would increase lipogenesis and glucose absorption in omental adipose tissue and may, therefore, have therapeutic utility in the prevention of obesity (Soldavini and Kaunitz, 2013). Thus, although optimal concentrations of SCFAs in the lumen of the colon would be essential for the maintenance of health, these concentrations can be reduced under various conditions such as the intake of a low-fiber diet and/or chronic use of antibiotics (Ganapathy et al., 2013).

There are different molecular mechanisms and cell targets involved in the SCFA-mediated protective effects, including the stimulation of the host's intestinal defenses (Raqib et al., 2012), direct and/or indirect effects on bacterial colonization and toxin production (Fukuda et al., 2012; Rivera-Chávez et al., 2016), and increased TJ function (Fachi et al., 2019). For example, SCFAs might exert protective effects against enteric pathogen colonization inducing the production of antimicrobial peptide LL37, as demonstrated in the HT-29 cell line (Termén et al., 2008). On the other hand, SCFAs can also have protective effects acting on the bacteria themselves, e.g., propionate represses Salmonella Pathogenicity Island 1 (SPI-1), decreasing its virulence (Hung et al., 2013), and butyrate strongly inhibits virulence factor production in Listeria monocytogenes (Sun et al., 2012). Butyrate treatment in a Clostridium difficile infection model increased the expression of genes associated with TJ proteins, including claudin-1 and occludin (Fachi et al., 2019). Due to this antimicrobial activity, SCFAs have promising applications in food safety and human health.

\section{Toxins That Damage the TJ: Zonula Occludens Toxin}

While many bacterial pathogens produce an array of virulence factors that affect the integrity of the epithelium during infection, in this review, we focused on those that affect TJ. For example, Entamoeba histolytica produces cysteine protease EhCP-A5 that induces secretion of IFN- $\gamma$, TNF- $\alpha$, and IL-13, which correlates with an increase in $\mathrm{TJ}$ permeability by altered expression of claudin-2, occludin, and ZO-1 (Kissoon-Singh et al., 2013). Helicobacter pylori transfers the cytotoxin-associated gene A (CagA) oncoprotein into gastric epithelial cells (Tohidpour, 2016; Camilo et al., 2017). CagA interacts with ZO-1 and junctional adhesion molecule, disturbing the composition and function of the apical junction complex (Tohidpour, 2016; Camilo et al., 2017). Clostridium difficile, the major cause of antibiotic-associated diarrhea and pseudomembranous colitis, produces exotoxin $A(\operatorname{Tcd} A)$ and exotoxin B $(\operatorname{TcdB})$, which 
inactivate specific Rho and Ras GTPases affecting downstream pathways, including cytoskeleton organization (Chandrasekaran and Lacy, 2017; Papatheodorou et al., 2018; Fachi et al., 2019). The disruption of the cellular actin structure leads to the death of IECs, the loss of barrier function, and, consequently, a profound inflammatory response (Fachi et al., 2019).

Another toxin secreted by different human pathogens is zonula occludens toxin (Zot). Zot was first discovered in Vibrio cholerae, and has been described to mimic zonulin (Fasano et al., 1995). Zot is also used by other pathogens, such as Campylobacter concisus (Kaakoush et al., 2010, 2014; Mahendran et al., 2016) and Neisseria meningitidis, to increase tissue permeability (Fasano, 2012). V. cholerae Zot increases ZO-1 phosphorylation via PKC $\alpha$, causing a selective disconnection of ZO-1 from occludin and claudin-1, opening the $\mathrm{TJ}$, and increasing intestinal permeability (Goldblum et al., 2011; Fasano, 2012). Zot induces cytoskeletal rearrangement, redistributing F-actin filaments (Fasano, 2012; Lemmer and Hamman, 2013) and altering TEER in Caco-2 cell monolayers (Goldblum et al., 2011).

Zot-type toxins have also been found in Vibrio parahaemolyticus and Vibrio vulnificus (Castillo et al., 2018a,b; Pérez-Reytor et al., 2018), both human pathogens. According to our recent studies, Zot would be associated with the actin cytoskeletal disturbances observed in Caco-2 cells after infection with a non-toxigenic strain of V. parahaemolyticus (Pérez-Reytor et al., 2020). On the other hand, it has been hypothesized that C. concisus disrupts gastrointestinal epithelium, driving a dysregulated immune response that results in chronic inflammation in the intestine (Mahendran et al., 2011; Zhang et al., 2014; O'Brien, 2017). The analysis of samples from the oral cavity of patients with IBD showed the presence of two Zot-encoding genes in the C. concisus strains, suggesting that Zot may play a critical role in the pathogenesis of these bacteria (Kaakoush et al., 2014; Liu et al., 2016). Studies by Mahendran et al. (2016) showed that Zot from C. concisus causes prolonged damage to the intestinal epithelial barrier, produces apoptosis, and increases the production of TNF- $\alpha$ and IL- 8 by epithelial cells and macrophages. Thus, understanding how these pathogens disrupt the epithelial barrier is essential to propose alternative treatments to improve the symptoms of the disease.

\section{CONCLUSION AND FUTURE DIRECTIONS}

As discussed above, SCFAs can diminish the severity and span of intestinal infections caused by different pathogens, not only regulating bacterial virulence but also improving membrane barrier function enhancing TJ proper functioning. The generation of beneficial SCFAs in the gut can be optimized with nutritional interventions such as the intake of appropriate prebiotics (complex carbohydrates that can be fermented by enteric bacteria) and probiotics (living bacteria that promote gut health); however, there is limited evidence indicating clinical improvement. Additionally, oral formulations of butyric acid have been studied, such as tributyrin (a butyric acid triglyceride; Edelman et al., 2003; Cresci et al., 2013). Some of the beneficial effects of probiotics are listed in Table 1.

Overall, although studies demonstrate that SCFAs serve as protective and anti-inflammatory agents in the intestine, the underlying molecular mechanisms remain poorly understood (Russo et al., 2019). Therefore, it is of great interest to determine the mechanisms involved in the protective function of SCFAs, to develop new therapeutic strategies against bacterial toxinstriggered intestinal damage. In this sense, we propose that SCFAs, signaling through GPCRs, activate PKC $\beta$ which phosphorylates ZO-1, allowing its reconnection with anchor proteins and actin cytoskeleton, recovering the barrier function affected by Zot-like toxins (Figure 1).

TABLE 1 | Summary of probiotics effects on epithelial barrier function in vitro and in vivo.

\begin{tabular}{|c|c|c|c|}
\hline Probiotic & Effect in epithelial barrier & Model & References \\
\hline Bifidobacterium longum* & $\begin{array}{l}\text { Increase the production of acetate and prevent the reduction in TEER } \\
\text { resulting from E. coli O157-induced cell death. }\end{array}$ & Caco-2 & Fukuda et al., 2011, 2012 \\
\hline Bacteroides thetaiotaomicron* & $\begin{array}{l}\text { Acetate-producing bacteria, favors goblet cell differentiation and mucus } \\
\text { secretion. }\end{array}$ & Rats & Wrzosek et al., 2013 \\
\hline Faecalibacterium prausnitzii* & $\begin{array}{l}\text { Acetate consumer and butyrate-producing bacteria, modulates the } \\
\text { intestinal mucus barrier when supplemented in combination with } B \text {. } \\
\text { thetaiotaomicron. }\end{array}$ & Rats & Wrzosek et al., 2013 \\
\hline Lactobacillus casei** $^{* *}$ & $\begin{array}{l}\text { Reverses the cytokine-induced dysfunction of TEER, epithelial } \\
\text { permeability, and ZO-1 expression. }\end{array}$ & Caco-2 & Eun et al., 2011 \\
\hline B. animalis ssp. lactis CNCM-I2494** & $\begin{array}{l}\text { Protects barrier integrity by restoring intestinal permeability, colonic goblet } \\
\text { cell populations, and cytokine levels. Furthermore, normalizes the level of } \\
\text { several TJ proteins, in particular claudin- } 4 \text {. }\end{array}$ & Mice & Martín et al., 2016 \\
\hline Lactobacillus plantarum ZLP001* & $\begin{array}{l}\text { Modulates butyrate-producing enteric microbiota to induce the expression } \\
\text { of epithelial host-defense peptides and to enhance intestinal Lactobacillus } \\
\text { abundance to improve the gut microbiota composition and reinforce TJs. }\end{array}$ & Weaned piglets & Wang et al., 2018 \\
\hline L. acidophilus* & Increases TEER, decreases permeability, and induces the activation of & Caco-2 & Resta-Lenert and Barrett, 2003 \\
\hline Streptococcus thermophilus* & $\begin{array}{l}\text { occludin and ZO-1, shown by increased levels of phosphorylated } \\
\text { proteins. }\end{array}$ & HT-29 & \\
\hline
\end{tabular}

*Probiotics that are part of the human intestinal microbiota.

${ }^{* *}$ Probiotics that, normally, are not present in the human intestinal microbiota. 


\section{AUTHOR CONTRIBUTIONS}

DP-R and KG conceived the idea. DP-R, CP, EK, and KG wrote the manuscript. All the authors read, discussed, and approved the final version of this manuscript.

\section{REFERENCES}

Anderson, J. M., and Van Itallie, C. M. (2009). Physiology and function of the tight junction. Cold Spring Harb. Perspect. Biol. 1:a002584. doi: 10.1101/ cshperspect.a002584

Banan, A., Fields, J. Z., Talmage, D. A., Zhang, Y., and Keshavarzian, A. (2001). PKC- $\beta 1$ mediates EGF protection of microtubules and barrier of intestinal monolayers against oxidants. Am. J. Physiol. Gastrointest. Liver Physiol. 281, G833-G847. doi: 10.1152/ajpgi.2001.281.3.G833

Basuroy, S., Sheth, P., Kuppuswamy, D., Balasubramanian, S., Ray, R. M., and Rao, R. K. (2003). Expression of kinase-inactive c-Src delays oxidative stressinduced disassembly and accelerates calcium-mediated reassembly of tight junctions in the Caco-2 cell monolayer. J. Biol. Chem. 278, 11916-11924. doi: $10.1074 / j b c . M 211710200$

Camilo, V., Sugiyama, T., and Touati, E. (2017). Pathogenesis of Helicobacter pylori infection. Helicobacter 22, 1-6. doi: 10.1111/hel.12405

Cario, E., Gerken, G., and Podolsky, D. K. (2007). Toll-like receptor 2 controls mucosal inflammation by regulating epithelial barrier function. Gastroenterol. 132, 1359-1374. doi: 10.1053/j.gastro.2007.02.056

Castillo, D., Kauffman, K., Hussain, F., Kalatzis, P., Rørbo, N., Polz, M. F., et al. (2018a). Widespread distribution of prophage-encoded virulence factors in marine Vibrio communities. Sci. Rep. 8:9973. doi: 10.1038/s41598-01828326-9

Castillo, D., Pérez-Reytor, D., Plaza, N., Ramírez-Araya, S., Blondel, C. J., Corsini, G., et al. (2018b). Exploring the genomic traits of non-toxigenic Vibrio parahaemolyticus strains isolated in southern Chile. Front. Microbiol. 9:161. doi: $10.3389 /$ fmicb.2018.00161

Ceelen, L., Haesebrouck, F., Vanhaecke, T., Rogiers, V., and Vinken, M. (2011). Modulation of connexin signaling by bacterial pathogens and their toxins. Cell. Mol. Life Sci. 68, 3047-3064. doi: 10.1007/s00018-011-0737-z

Chandrasekaran, R., and Lacy, D. B. (2017). The role of toxins in Clostridium difficile infection. FEMS Microbiol. Rev. 41, 723-750. doi: 10.1093/femsre/ fux048

Chen, Y.-H., and Lu, G. (2003). "Association of Nonreceptor tyrosine kinase c-Yes with tight junction protein occludin by coimmunoprecipitation assay" in Cancer Cell Signaling. New Jersey: Humana Press, 127-132.

Cox, M. A., Jackson, J., Stanton, M., Rojas-Triana, A., Bober, L., Laverty, M., et al. (2009). Short-chain fatty acids act as antiinflammatory mediators by regulating prostaglandin $\mathrm{E}(2)$ and cytokines. World J. Gastroenterol. 15, 5549-5557. doi: $10.3748 /$ wjg. 15.5549

Cresci, G., Nagy, L. E., and Ganapathy, V. (2013). Lactobacillus GG and tributyrin supplementation reduce antibiotic-induced intestinal injury. J. Parenter. Enter. Nutr. 37, 763-774. doi: 10.1177/0148607113486809

D’Souza, W. N., Douangpanya, J., Mu, S., Jaeckel, P., Zhang, M., Maxwell, J. R., et al. (2017). Differing roles for short chain fatty acids and GPR43 agonism in the regulation of intestinal barrier function and immune responses. PLoS One 12:e0180190. doi: 10.1371/journal.pone.0180190

Edelman, M. J., Bauer, K., Khanwani, S., Tait, N., Trepel, J., Karp, J., et al. (2003). Clinical and pharmacologic study of tributyrin: an oral butyrate prodrug. Cancer Chemother. Pharmacol. 51, 439-444. doi: 10.1007/ s00280-003-0580-5

Eun, C. S., Kim, Y. S., Han, D. S., Choi, J. H., Lee, A. R., and Park, Y. K. (2011). Lactobacillus casei prevents impaired barrier function in intestinal epithelial cells. APMIS 119, 49-56. doi: 10.1111/j.1600-0463.2010.02691.x

Fachi, J. L., Felipe, J. d. S., Pral, L. P., da Silva, B. K., Corrêa, R. O., de Andrade, M. C. P., et al. (2019). Butyrate protects mice from Clostridium difficile-induced colitis through an HIF-1-dependent mechanism. Cell Rep. 27, 750.e7-761.e7. doi: 10.1016/j.celrep.2019.03.054

Fan, Y., and Pedersen, O. (2020). Gut microbiota in human metabolic health and disease. Nat. Rev. Microbiol. 19, 55-71. doi: 10.1038/s41579-020-0433-9

\section{FUNDING}

This work was supported by Fondecyt (Fondo Nacional de Desarrollo Científico y Tecnológico) Regular (grant no. $\mathrm{N}^{\circ} 1190957$ ) and Fondo de Apoyo a la Investigación 2020 (grant no. DIUA188-2020).

Fasano, A. (2002). Toxins and the gut: role in human disease. Gut 50, 9-14. doi: 10.1136/gut.50.suppl_3.iii9

Fasano, A. (2012). Intestinal permeability and its regulation by zonulin: diagnostic and therapeutic implications. Clin. Gastroenterol. Hepatol. 10, 1096-1100. doi: $10.1016 /$ j.cgh.2012.08.012

Fasano, A., Fiorentini, C., Donelli, G., Uzzau, S., Kaper, J. B., Margaretten, K., et al. (1995). Zonula occludens toxin modulates tight junctions through protein kinase $\mathrm{C}$-dependent actin reorganization, in vitro. J. Clin. Invest. 96, 710-720. doi: 10.1172/JCI118114

Feng, W., Wu, Y., Chen, G., Fu, S., Li, B., Huang, B., et al. (2018). Sodium butyrate attenuates diarrhea in weaned piglets and promotes tight junction protein expression in colon in a GPR109A-dependent manner. Cell. Physiol. Biochem. 47, 1617-1629. doi: 10.1159/000490981

Frampton, J., Murphy, K. G., Frost, G., and Chambers, E. S. (2020). Shortchain fatty acids as potential regulators of skeletal muscle metabolism and function. Nat. Metab. 2, 840-848. doi: 10.1038/s42255-020-0188-7

Fukuda, S., Toh, H., Hase, K., Oshima, K., Nakanishi, Y., Yoshimura, K., et al. (2011). Bifidobacteria can protect from enteropathogenic infection through production of acetate. Nature 469, 543-547. doi: 10.1038/nature09646

Fukuda, S., Toh, H., Taylor, T. D., Ohno, H., and Hattori, M. (2012). Acetateproducing bifidobacteria protect the host from enteropathogenic infection via carbohydrate transporters. Gut Microbes 3, 449-454. doi: 10.4161/ gmic. 21214

Ganapathy, V., Thangaraju, M., Prasad, P. D., Martin, P. M., and Singh, N. (2013). Transporters and receptors for short-chain fatty acids as the molecular link between colonic bacteria and the host. Curr. Opin. Pharmacol. 13, 869-874. doi: 10.1016/j.coph.2013.08.006

Goldblum, S. E., Rai, U., Tripathi, A., Thakar, M., De Leo, L., Di Toro, N., et al. (2011). The active Zot domain (aa 288-293) increases ZO-1 and myosin $1 \mathrm{C}$ serine/threonine phosphorylation, alters interaction between $\mathrm{ZO}-1$ and its binding partners, and induces tight junction disassembly through proteinase activated receptor 2 activation. FASEB J. 25, 144-158. doi: 10.1096/ f. $10-158972$

Gupta, N., Martin, P. M., Prasad, P. D., and Ganapathy, V. (2006). SLC5A8 (SMCT1)-mediated transport of butyrate forms the basis for the tumor suppressive function of the transporter. Life Sci. 78, 2419-2425. doi: 10.1016/j. lfs. 2005.10 .028

Hiippala, K., Jouhten, H., Ronkainen, A., Hartikainen, A., Kainulainen, V., Jalanka, J., et al. (2018). The potential of gut commensals in reinforcing intestinal barrier function and alleviating inflammation. Nutrients 10:988. doi: $10.3390 /$ nu10080988

Hiroko, H., Kamikado, K., Ryo, A., Su, N., and Tomohiko, N. (2020). Bifidobacterium animalis subsp. lactis GCL2505 modulates host energy metabolism via the short-chain fatty acid receptor GPR43. Sci. Rep. 10:4158. doi: 10.1038/s41598-020-60984-6

Hung, C.-C., Garner, C. D., Slauch, J. M., Dwyer, Z. W., Lawhon, S. D., Frye, J. G., et al. (2013). The intestinal fatty acid propionate inhibits Salmonella invasion through the post-translational control of HilD. Mol. Microbiol. 87, 1045-1060. doi: 10.1111/mmi.12149

Jain, S., Suzuki, T., Seth, A., Samak, G., and Rao, R. (2011). Protein kinase CS phosphorylates occludin and promotes assembly of epithelial tight junctions. Biochem. J. 437, 289-299. doi: 10.1042/BJ20110587

Kaakoush, N. O., Man, S. M., Lamb, S., Raftery, M. J., Wilkins, M. R., and Mitchell, H. (2010). The secretome of Campylobacter concisus. FEBS J. 277, 1606-1617. doi: 10.1111/j.1742-4658.2010.07587.x

Kaakoush, N. O., Mitchell, H. M., and Man, S. M. (2014). Role of emerging Campylobacter species in inflammatory bowel diseases. Inflamm. Bowel Dis. 20, 2189-2197. doi: 10.1097/MIB.0000000000000074

Karl, J. P., Hatch, A. M., Arcidiacono, S. M., Pearce, S. C., Pantoja-Feliciano, I. G., Doherty, L. A., et al. (2018). Effects of psychological, environmental and 
physical stressors on the gut microbiota. Front. Microbiol. 9:2013. doi: 10.3389/ fmicb.2018.02013

Kim, S., Kim, J. H., Park, B. O., and Kwak, Y. S. (2014). Perspectives on the therapeutic potential of short-chain fatty acid receptors. BMB Rep. 47, 173-178. doi: 10.5483/BMBRep.2014.47.3.272

Kimura, I., Ozawa, K., Inoue, D., Imamura, T., Kimura, K., Maeda, T., et al. (2013). The gut microbiota suppresses insulin-mediated fat accumulation via the short-chain fatty acid receptor GPR43. Nat. Commun. 4, 1-12. doi: $10.1038 /$ ncomms 2852

Kissoon-Singh, V., Moreau, F., Trusevych, E., and Chadee, K. (2013). Entamoeba histolytica exacerbates epithelial tight junction permeability and proinflammatory responses in Muc2-/- mice. Am. J. Pathol. 182, 852-865. doi: 10.1016/j. ajpath.2012.11.035

Lemmer, H. J., and Hamman, J. H. (2013). Paracellular drug absorption enhancement through tight junction modulation. Expert Opin. Drug Deliv. 10, 103-114. doi: 10.1517/17425247.2013.745509

Li, M., van Esch, B. C. A. M., Henricks, P. A. J., Folkerts, G., and Garssen, J. (2018). The anti-inflammatory effects of short chain fatty acids on lipopolysaccharide- or tumor necrosis factor $\alpha$-stimulated endothelial cells via activation of GPR41/43 and inhibition of HDACs. Front. Pharmacol. 9:533. doi: 10.3389/fphar.2018.00533

Lin, M. Y., de Zoete, M. R., van Putten, J. P. M., and Strijbis, K. (2015). Redirection of epithelial immune responses by short-chain fatty acids through inhibition of histone deacetylases. Front. Immunol. 6:554. doi: 10.3389/fimmu.2015.00554

Liu, F., Lee, H., Lan, R., and Zhang, L. (2016). Zonula occludens toxins and their prophages in Campylobacter species. Gut Pathog. 8:43. doi: 10.1186/ s13099-016-0125-1

Louis, P., and Flint, H. J. (2009). Diversity, metabolism and microbial ecology of butyrate-producing bacteria from the human large intestine. FEMS Microbiol. Lett. 294, 1-8. doi: 10.1111/j.1574-6968.2009.01514.x

Louis, P., and Flint, H. J. (2017). Formation of propionate and butyrate by the human colonic microbiota. Environ. Microbiol. 19, 29-41. doi: $10.1111 / 1462-2920.13589$

Ma, T. Y., Boivin, M. A., Ye, D., Pedram, A., and Said, H. M. (2005). Mechanism of TNF- $\alpha$ modulation of Caco-2 intestinal epithelial tight junction barrier: role of myosin light-chain kinase protein expression. Am. J. Physiol. Gastrointest. Liver Physiol. 288, 422-430. doi: 10.1152/ajpgi.00412.2004

Macia, L., Tan, J., Vieira, A. T., Leach, K., Stanley, D., Luong, S., et al. (2015). Metabolite-sensing receptors GPR43 and GPR109A facilitate dietary fibreinduced gut homeostasis through regulation of the inflammasome. Nat. Commun. 6:6734. doi: 10.1038/ncomms7734

Mahendran, V., Liu, F., Riordan, S. M., Grimm, M. C., Tanaka, M. M., and Zhang, L. (2016). Examination of the effects of Campylobacter concisus zonula occludens toxin on intestinal epithelial cells and macrophages. Gut Pathog. 8:18. doi: 10.1186/s13099-016-0101-9

Mahendran, V., Riordan, S. M., Grimm, M. C., Tran, T. A. T., Major, J., Kaakoush, N. O., et al. (2011). Prevalence of Campylobacter species in adult Crohn's disease and the preferential colonization sites of Campylobacter species in the human intestine. PLoS One 6:e25417. doi: 10.1371/journal. pone. 0025417

Martín, R., Laval, L., Chain, F., Miquel, S., Natividad, J., Cherbuy, C., et al. (2016). Bifidobacterium animalis ssp. lactis CNCM-I2494 restores gut barrier permeability in chronically low-grade inflamed mice. Front. Microbiol. 7:608. doi: $10.3389 /$ fmicb.2016.00608

Martinez-Guryn, K., Hubert, N., Frazier, K., Urlass, S., Musch, M. W., Ojeda, P., et al. (2018). Small intestine microbiota regulate host digestive and absorptive adaptive responses to dietary lipids. Cell Host Microbe 23, 458.e5-469.e5. doi: 10.1016/j.chom.2018.03.011

Maynard, C. L., Elson, C. O., Hatton, R. D., and Weaver, C. T. (2012). Reciprocal interactions of the intestinal microbiota and immune system. Nature 489, 231-241. doi: 10.1038/nature11551

Miao, W., Wu, X., Wang, K., Wang, W., Wang, Y., Li, Z., et al. (2016). Sodium butyrate promotes reassembly of tight junctions in Caco-2 monolayers involving inhibition of MLCK/MLC2 pathway and phosphorylation of $\mathrm{PKC} \beta 2$. Int. J. Mol. Sci. 17, 1-12. doi: 10.3390/ijms17101696

O'Brien, S. J. (2017). The consequences of campylobacter infection. Curr. Opin. Gastroenterol. 33, 14-20. doi: 10.1097/MOG.0000000000000329

O'Connor, E. M. (2013). The role of gut microbiota in nutritional status. Curr. Opin. Clin. Nutr. Metab. Care 16, 509-516. doi: 10.1097/MCO.0b013e3283638eb3
Pan, P., Oshima, K., Huang, Y. W., Agle, K. A., Drobyski, W. R., Chen, X., et al. (2018). Loss of FFAR2 promotes colon cancer by epigenetic dysregulation of inflammation suppressors. Int. J. Cancer 143, 886-896. doi: 10.1002/ijc.31366

Papatheodorou, P., Barth, H., Minton, N., and Aktories, K. (2018). Cellular uptake and mode-of-action of Clostridium difficile toxins. Adv. Exp. Med. Biol. 1050, 77-96. doi: 10.1007/978-3-319-72799-8_6

Parada Venegas, D., De la Fuente, M. K., Landskron, G., González, M. J., Quera, R., Dijkstra, G., et al. (2019). Short chain fatty acids (SCFAs)-mediated gut epithelial and immune regulation and its relevance for inflammatory bowel diseases. Front. Immunol. 10:277. doi: 10.3389/fimmu.2019.00277

Paul, D., Dey, T. K., Chakraborty, A., and Dhar, P. (2018). "Promising functional lipids for therapeutic applications," in Handbook of Food Bioengineering. eds. A. M. Grumezescu and A. M. Holban (London, UK: Academic Press), 413-449.

Peng, L., Li, Z.-R., Green, R. S., Holzman, I. R., and Lin, J. (2009). Butyrate enhances the intestinal barrier by facilitating tight junction assembly via activation of AMP-activated protein kinase in Caco-2 cell monolayers. J. Nutr. 139, 1619-1625. doi: 10.3945/jn.109.104638

Pérez-Reytor, D., Jaña, V., Pavez, L., Navarrete, P., and García, K. (2018). Accessory toxins of vibrio pathogens and their role in epithelial disruption during infection. Front. Microbiol. 9:2248. doi: 10.3389/fmicb.2018.02248

Pérez-Reytor, D., Pavón, A., Lopez-Joven, C., Ramírez-Araya, S., Peña-Varas, C., Plaza, N., et al. (2020). Analysis of the zonula occludens toxin found in the genome of the chilean non-toxigenic Vibrio parahaemolyticus strain PMC53.7. Front. Cell. Infect. Microbiol. 10:482. doi: 10.3389/fcimb.2020.00482

Pingitore, A., Gonzalez-Abuin, N., Ruz-Maldonado, I., Huang, G. C., Frost, G., and Persaud, S. J. (2019). Short chain fatty acids stimulate insulin secretion and reduce apoptosis in mouse and human islets in vitro: role of free fatty acid receptor 2. Diabetes Obes. Metab. 21, 330-339. doi: 10.1111/dom.13529

Raqib, R., Sarker, P., Mily, A., Alam, N. H., Arifuzzaman, A. S. M., Rekha, R. S., et al. (2012). Efficacy of sodium butyrate adjunct therapy in shigellosis: a randomized, double-blind, placebo-controlled clinical trial. BMC Infect. Dis. 12:111. doi: $10.1186 / 1471-2334-12-111$

Resta-Lenert, S., and Barrett, K. E. (2003). Live probiotics protect intestinal epithelial cells from the effects of infection with enteroinvasive Escherichia coli (EIEC). Gut 52, 988-997. doi: 10.1136/gut.52.7.988

Rickard, K. L., Gibson, P. R., Wilson, N. J., Mariadason, J. M., and Phillips, W. A. (2000). Short-chain fatty acids reduce expression of specific protein kinase C isoforms in human colonic epithelial cells. J. Cell. Physiol. 182, 222-231. doi: 10.1002/(SICI)1097-4652(200002)182:2<222::AID-JCP11>3.0.CO;2-B

Rivera-Chávez, F., Zhang, L. F., Faber, F., Lopez, C. A., Byndloss, M. X., Olsan, E. E., et al. (2016). Depletion of butyrate-producing clostridia from the gut microbiota drives an aerobic luminal expansion of Salmonella. Cell Host Microbe 19, 443-454. doi: 10.1016/j.chom.2016.03.004

Russo, E., Giudici, F., Fiorindi, C., Ficari, F., Scaringi, S., and Amedei, A. (2019). Immunomodulating activity and therapeutic effects of short chain fatty acids and tryptophan post-biotics in inflammatory bowel disease. Front. Immunol. 10:2754. doi: 10.3389/fimmu.2019.02754

Salama, N. N., Eddington, N. D., and Fasano, A. (2006). Tight junction modulation and its relationship to drug delivery. Adv. Drug Deliv. Rev. 58, 15-28. doi: 10.1016/j.addr.2006.01.003

Sapone, A., De Magistris, L., Pietzak, M., Clemente, M. G., Tripathi, A., Cucca, F., et al. (2006). Zonulin upregulation is associated with increased gut permeability in subjects with type 1 diabetes and their relatives. Diabetes 55, 1443-1449. doi: $10.2337 / \mathrm{db} 05-1593$

Seth, A., Yan, F., Polk, D. B., and Rao, R. K. (2008). Probiotics ameliorate the hydrogen peroxide-induced epithelial barrier disruption by a PKC- and MAP kinase-dependent mechanism. Am. J. Physiol. Gastrointest. Liver Physiol. 294, G1060-G1069. doi: 10.1152/ajpgi.00202.2007

Singh, N., Gurav, A., Sivaprakasam, S., Brady, E., Padia, R., Shi, H., et al. (2014). Activation of Gpr109a, receptor for niacin and the commensal metabolite butyrate, suppresses colonic inflammation and carcinogenesis. Immunity 40, 128-139. doi: 10.1016/j.immuni.2013.12.007

Sokol, H., Lepage, P., Seksik, P., Doré, J., and Marteau, P. (2007). Molecular comparison of dominant microbiota associated with injured versus healthy mucosa in ulcerative colitis. Gut 56, 152-154. doi: 10.1136/gut.2006.109686

Soldavini, J., and Kaunitz, J. D. (2013). Pathobiology and potential therapeutic value of intestinal short-chain fatty acids in gut inflammation and obesity. Dig. Dis. Sci. 58, 2756-2766. doi: 10.1007/s10620-013-2744-4 
Sturgeon, C., and Fasano, A. (2016). Zonulin, a regulator of epithelial and endothelial barrier functions, and its involvement in chronic inflammatory diseases. Tissue Barriers 4, 1-19. doi: 10.1080/21688370.2016.1251384

Sun, Y., Wilkinson, B. J., Standiford, T. J., Akinbi, H. T., and O'Riordan, M. X. D. (2012). Fatty acids regulate stress resistance and virulence factor production for Listeria monocytogenes. J. Bacteriol. 194, 5274-5284. doi: 10.1128/JB.00045-12

Sun, M., Wu, W., Liu, Z., and Cong, Y. (2017). Microbiota metabolite short chain fatty acids, GPCR, and inflammatory bowel diseases. J. Gastroenterol. 52, 1-8. doi: 10.1007/s00535-016-1242-9

Suzuki, T., Yoshida, S., and Hara, H. (2008). Physiological concentrations of short-chain fatty acids immediately suppress colonic epithelial permeability. Br. J. Nutr. 100, 297-305. doi: 10.1017/S0007114508888733

Termén, S., Tollin, M., Rodriguez, E., Sveinsdóttir, S. H., Jóhannesson, B., Cederlund, A., et al. (2008). PU.1 and bacterial metabolites regulate the human gene CAMP encoding antimicrobial peptide LL-37 in colon epithelial cells. Mol. Immunol. 45, 3947-3955. doi: 10.1016/j.molimm.2008.06.020

Tohidpour, A. (2016). CagA-mediated pathogenesis of Helicobacter pylori. Microb. Pathog. 93, 44-55. doi: 10.1016/j.micpath.2016.01.005

Ugalde-Silva, P., Gonzalez-Lugo, O., and Navarro-Garcia, F. (2016). Tight junction disruption induced by type 3 secretion system effectors injected by enteropathogenic and enterohemorrhagic Escherichia coli. Front. Cell. Infect. Microbiol. 6:87. doi: 10.3389/fcimb.2016.00087

Ulven, T. (2012). Short-chain free fatty acid receptors FFA2/GPR43 and FFA3/ GPR41 as new potential therapeutic targets. Front. Endocrinol. 3:111. doi: $10.3389 /$ fendo.2012.00111

Valenzano, M. C., DiGuilio, K., Mercado, J., Teter, M., To, J., Ferraro, B., et al. (2015). Remodeling of tight junctions and enhancement of barrier integrity of the CACO-2 intestinal epithelial cell layer by micronutrients. PLoS One 10:e0133926. doi: 10.1371/journal.pone.0133926

Vergnolle, N. (2005). Clinical relevance of proteinase activated receptors (PARs) in the gut. Gut 54, 867-874. doi: 10.1136/gut.2004.048876

Wang, J., Ji, H., Wang, S., Liu, H., Zhang, W., Zhang, D., et al. (2018). Probiotic lactobacillus plantarum promotes intestinal barrier function by strengthening the epithelium and modulating gut microbiota. Front. Microbiol. 9:1953. doi: $10.3389 /$ fmicb. 2018.01953
Wang, H. B., Wang, P. Y., Wang, X., Wan, Y. L., and Liu, Y. C. (2012). Butyrate enhances intestinal epithelial barrier function via up-regulation of tight junction protein claudin-1 transcription. Dig. Dis. Sci. 57, 3126-3135. doi: 10.1007/s10620-012-2259-4

Wrzosek, L., Miquel, S., Noordine, M.-L., Bouet, S., Joncquel Chevalier-Curt, M., Robert, V., et al. (2013). Bacteroides thetaiotaomicron and Faecalibacterium prausnitzii influence the production of mucus glycans and the development of goblet cells in the colonic epithelium of a gnotobiotic model rodent. BMC Biol. 11:61. doi: 10.1186/1741-7007-11-61

Yan, H., and Ajuwon, K. M. (2017). Butyrate modifies intestinal barrier function in IPEC-J2 cells through a selective upregulation of tight junction proteins and activation of the Akt signaling pathway. PLoS One 12:e0179586. doi: 10.1371/journal.pone.0179586

Yap, Y. A., and Mariño, E. (2018). An insight into the intestinal web of mucosal immunity, microbiota, and diet in inflammation. Front. Immunol. 9:2617. doi: $10.3389 /$ fimmu.2018.02617

Ye, D., Ma, I., and Ma, T. Y. (2006). Molecular mechanism of tumor necrosis factor- $\alpha$ modulation of intestinal epithelial tight junction barrier. Am. J. Physiol. Gastrointest. Liver Physiol. 290, 496-504. doi: 10.1152/ajpgi. 00318.2005

Zhang, L., Lee, H., Grimm, M. C., Riordan, S. M., Day, A. S., and Lemberg, D. A. (2014). Campylobacter concisus and inflammatory bowel disease. World J. Gastroenterol. 20, 1259-1267. doi: 10.3748/wjg.v20.i5.1259

Conflict of Interest: The authors declare that the research was conducted in the absence of any commercial or financial relationships that could be construed as a potential conflict of interest.

Copyright (c 2021 Pérez-Reytor, Puebla, Karahanian and García. This is an open-access article distributed under the terms of the Creative Commons Attribution License (CC BY). The use, distribution or reproduction in other forums is permitted, provided the original author(s) and the copyright owner(s) are credited and that the original publication in this journal is cited, in accordance with accepted academic practice. No use, distribution or reproduction is permitted which does not comply with these terms. 